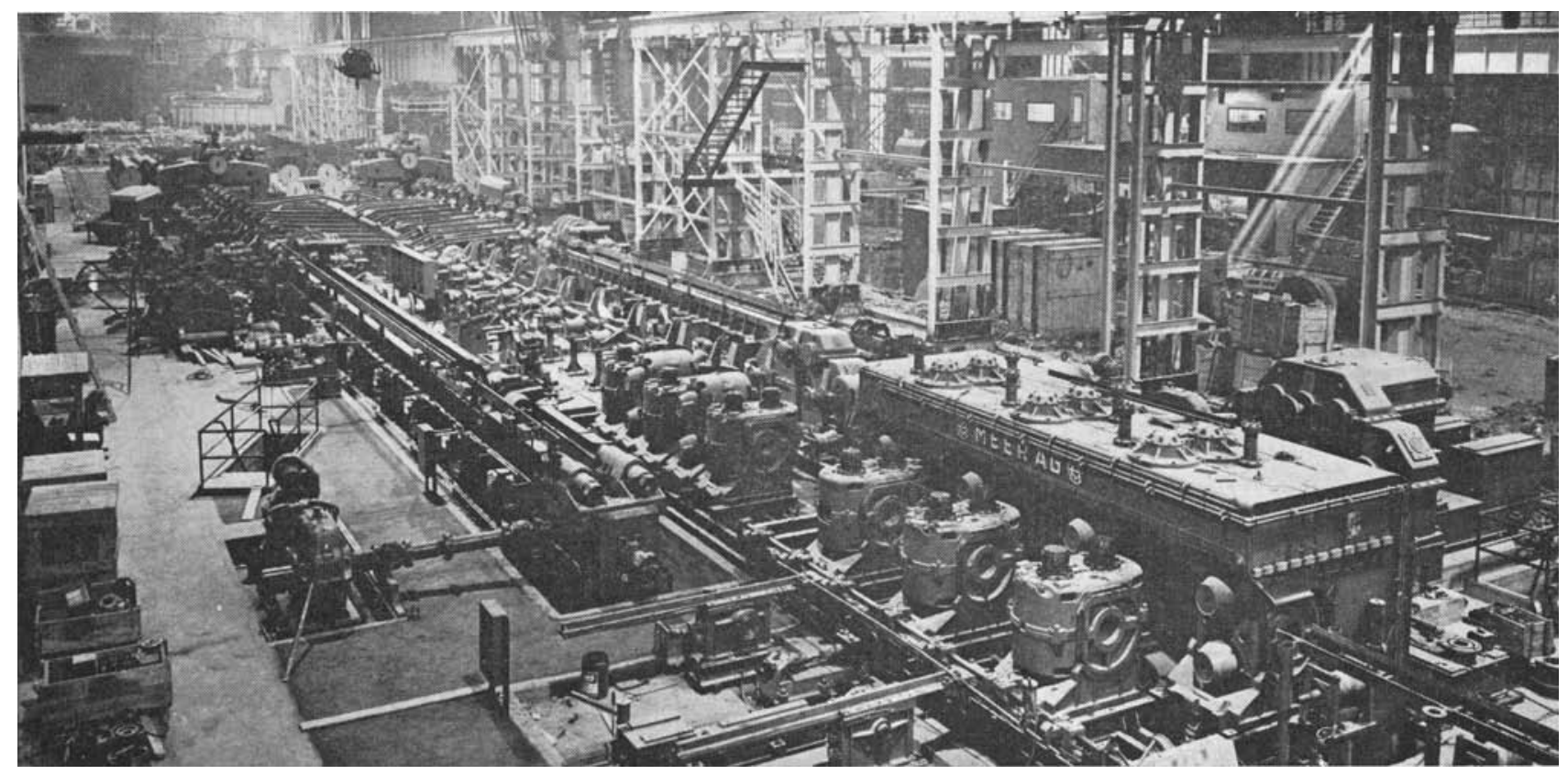

Fig. A-The reeler, to even up wall thickness, and a sizing mill, to secure an even diameter throughout' the tube, at the Mannesmann tube plant.

\title{
SEAMLESS TUBE PLANT OPENS IN CANADA
}

\begin{abstract}
A completely mechanized seamless steel tube mill of the Mannesmann type went into operation recently in Sault St. Marie, Ont., Canada. The world's first completely automatic tube mill, the plant was built by Mannesmann A. G. of Duesseldorf, Germany. Capacity of the new plant is estimated to be 225,000 tons of seamless tubes, $4 \frac{1 / 2}{2}$ to $103 / 4$ in. OD, per year.

Initially, billets are transported by Ross straddle carriers from the Algoma Steel plant, less than a quarter of a mile away. Oxygen-electric torches cut the billets to the proper length.

After Magnaglow inspection, the billets are heated to about $2250^{\circ} \mathrm{F}$ in a rotary hearth furnace. From here, the billets pass on to a Mannesmann rotary piercer. In the piercer, the billet is spirally and horizontally advanced between two oblique rolls, and held on center by top and bottom guide shoes. This cross-rolling action creates a combination of axial tensile stresses on the surface of the billet and tension and compression forces on the inner fibres, causing the hot steel to inwardly separate and form a center cavity.
\end{abstract}

In this manner the hollow bloom is formed. A piercing plug centrally located between the rolls and guide shoes forms the inner surface of the cavity. Plastic deformation of the steel during the piercing operation yields highly desirable physical properties and improved grain structure in the finished product.

After leaving the first piercing mill, the same process is repeated in the second piercing mill, elongating the hollow bloom and reducing the wall thickness. The tube, still hot, is then rolled twice in a plug mill between grooved rolls over a plug, to reduce the wall to the desired thickness.

The tube then passes through a reeler to achieve dimensional accuracy and a sizing mill produces an even outside diameter. After cooling, the pipe is conveyed to a rotary straightener. Thereafter, the pipe is carefully inspected for size, wall thickness, concentricity, and inside and outside surface quality.

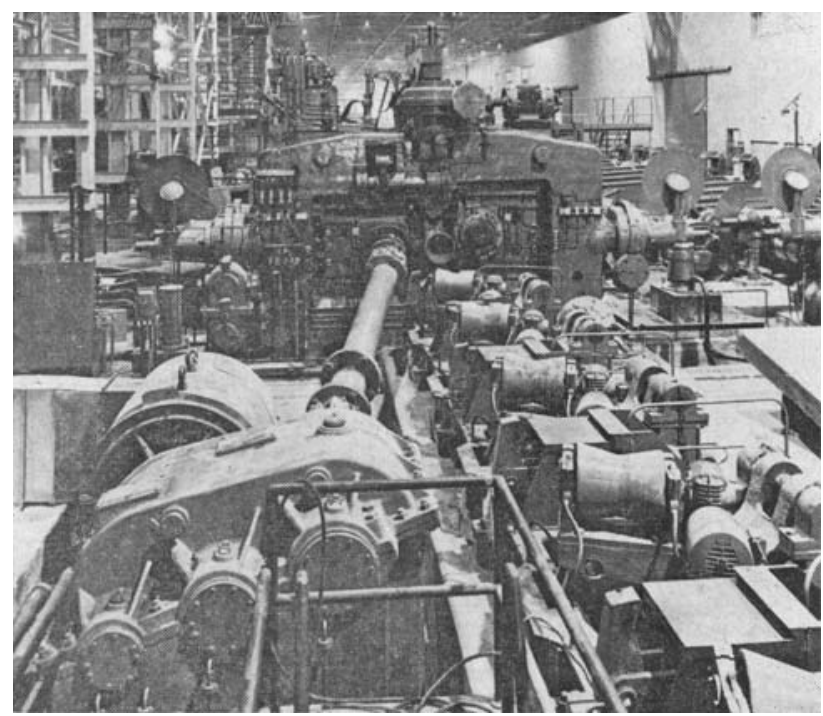

Fig. B-Above, the newly designed reeler provides a high degree of dimensional accuracy in seamless steel pipe production. 